J. Clin. Chem. Clin. Biochem.

Vol. 25, 1987, pp. 729-732

(C) 1987 Walter de Gruyter \& Co.

Berlin · New York

\title{
Selective Determination of Lactate Dehydrogenase Isoenzyme 1 in Serum after Inhibition by 1,6-Hexanediol
}

\author{
By K. Tanishima, E. Ohta, J. Mikami and S. Sumita \\ Division of Clinical Laboratory Sciences, School of Allied Medical Professions, Kanazawa University, Kanazawa, \\ Japan
}

(Received October 27, 1986/June 29, 1987)

\begin{abstract}
Summary: A rapid selective method for measuring the activity of lactate dehydrogenase isoenzyme LD-1 in serum by using 1,6-hexanediol as an inhibitor of the M-subunit was developed.

Hexanediol was added to serum at a final concentration of $0.7 \mathrm{~mol} / \mathrm{l}$. After incubation at $30^{\circ} \mathrm{C}$ for $15 \mathrm{~min}$, the activity was measured with an automatic analyser. The inter-assay coefficient of variation was $6.9 \%$ for the lactate dehydrogenase isoenzyme LD-1 measurement. The results obtained from the sera of 100 patients analysed by the proposed selective method and by the conventional electrophoretic method, respectively, showed an excellent correlation. This selective method was used to determine the lactate dehydrogenase isoenzyme LD-1 activity of sera from patients with acute myocardial infarction, and the results were correlated well with those obtained by the immunological, Roch Isomune method. Addition of 1,6-hexanediol did not affect the measurement of activities of other enzymes such as alkaline phosphatase, $\gamma$-glutamyltransferase, aspartate aminotransferase and alanine aminotransferase.
\end{abstract}

\section{Introduction}

Recently, many investigators have reported the use of lactate dehydrogenase (EC 1.1.1.27) isoenzymes and creatine kinase (EC 2.7.3.2) isoenzymes in suspected myocardial infarction $(1-3)$, and the precise, accurate and automated determination of lactate dehydrogenase isoenzyme activities in serum has been discussed (4-6).

We previously reported a manual method for measuring the activities of lactate dehydrogenase isoenzymes LD-1 and LD-2 in serum, involving 1,6-hexanediol as an inhibitor of the $\mathrm{M}$-subunit (7). The LD-1 and LD-2 isoenzymes were well discriminated from the other three isoenzymes (LD-3, LD-4, LD-5) by this method. Analytical recovery tests and correlation experiments with the conventional electrophoretic method supported the validity of the analysis with this inhibitor.

We applied this method to the assay of LD-1 isoenzyme activity in serum, using an automatic analyser.

\section{Materials and Methods}

We used serum samples taken for routine analysis in the Central Clinical Laboratory of our University Hospital. Total enzyme activity was measured by the continuous method with Concmitrate-LDH reagent (Chugai Pharmaceutical Co. Ltd., Japan) by the routine procedure using the Clinalyzer JCA-MS 24 (Nippon Denshi Electric Co. Ltd., Japan). This reagent contains $100 \mathrm{mmol} / 1$ phosphate buffer, $\mathrm{pH} 7.4,0.69 \mathrm{mmol} / \mathrm{l}$ pyruvate and $0.217 \mathrm{mmol} / \mathrm{N}$ NADH. Decrease of absorbance at 340 nm was read at $37^{\circ} \mathrm{C}$. Samples were read 2 min after starting the reaction.

We added one part of hexanediol stock solution to four parts of serum to yield a final appropriate concentration. After incubation at $30^{\circ} \mathrm{C}$ for $15 \mathrm{~min}$, we measured the enzyme activities in sera with the automatic analyser described above.

Manual measurement of the enzyme activity and electrophoresis of isoenzymes and subsequent staining of enzyme activity on "Microzone plus" electrophoresis membranes (Beckman Instruments, Inc., Fullerton, CA; Cat. No. 655420) were carried out according to the methods reported previously (7). The inhibitor, 1,6-hexanediol was of extra pure grade from Aldrich Chemical Co., Inc., Milwaukee, WI, USA.

Immunochemical determination of lactate dehydrogenase isoenzyme LD-1 activity was carried out by using the Roche Isomune-LD method (Roche Diagnostic Systems, Division of Hoffman-La Roche Inc., Nutley, NJ, USA). 


\section{Results}

\section{Procedure optimization}

To determine inhibition as a function of time and temperature, we measured manually lactate dehydrogenase activities in normal sera after inhibition with 1,6-hexanediol at several temperatures and after several different periods of incubation. From figure 1, it is evident that the residual catalytic concentration of lactate dehydrogenase remains constant after incubation for $15 \mathrm{~min}$ at $30^{\circ} \mathrm{C}$ at hexanediol concentrations of 500 to $700 \mathrm{mmol} / \mathrm{l}$, and remains constant for at least a further $15 \mathrm{~min}$. These levels after incubation at $30^{\circ} \mathrm{C}$ corresponded well to levels of LD-1 isoenzyme determined in normal serum by electrophoresis. At $25^{\circ} \mathrm{C}$, the time needed to attain these levels was increased. On the other hand, the activity was inhibited more rapidly and markedly at $37^{\circ} \mathrm{C}$.

In order to determine an appropriate concentration of inhibitor, we measured lactate dehydrogenase activities with the automatic analyser in normal sera and sera from patients with liver disease and myocardial infarction in the presence of different concentrations of 1,6-hexanediol; the resulting activities were compared with those obtained by the electrophoretic method (tab. 1). It is evident that the final concentration of hexanediol necessary to obtain the true value for LD-1 isoenzyme activity alone is 700 to 750 $\mathrm{mmol} / \mathrm{l}$. This hexanediol concentration of $700 \mathrm{mmol} / \mathrm{l}$ was used in the proposed selective method for measuring LD-1 isoenzyme activity.

\section{Precision study}

We studied the precision on the proposed method by using normal human serum, containing a total lactate dehydrogenase activity of $232 \mathrm{U} / 1$ and in which LD1 isoenzyme represented $25.5 \%$ of the total activity as determined by the electrophoretic method. Mean \pm standard deviation from 8 measurements of LD1 isoenzyme activity in this serum was $25.8 \pm 1.8 \%$, with an inter-assay coefficient of variation of $6.9 \%$.

\section{Method comparison}

The results obtained from the sera of 100 patients analysed by the proposed method and by a conventional electrophoretic method, respectively, were compared. LD-1 isoenzyme activities as measured by the former method $(y)$ and by latter $(x)$ correlated well (fig. 2). Twenty seven of these 100 patients had liver disease and 9 had myocardial infarction.

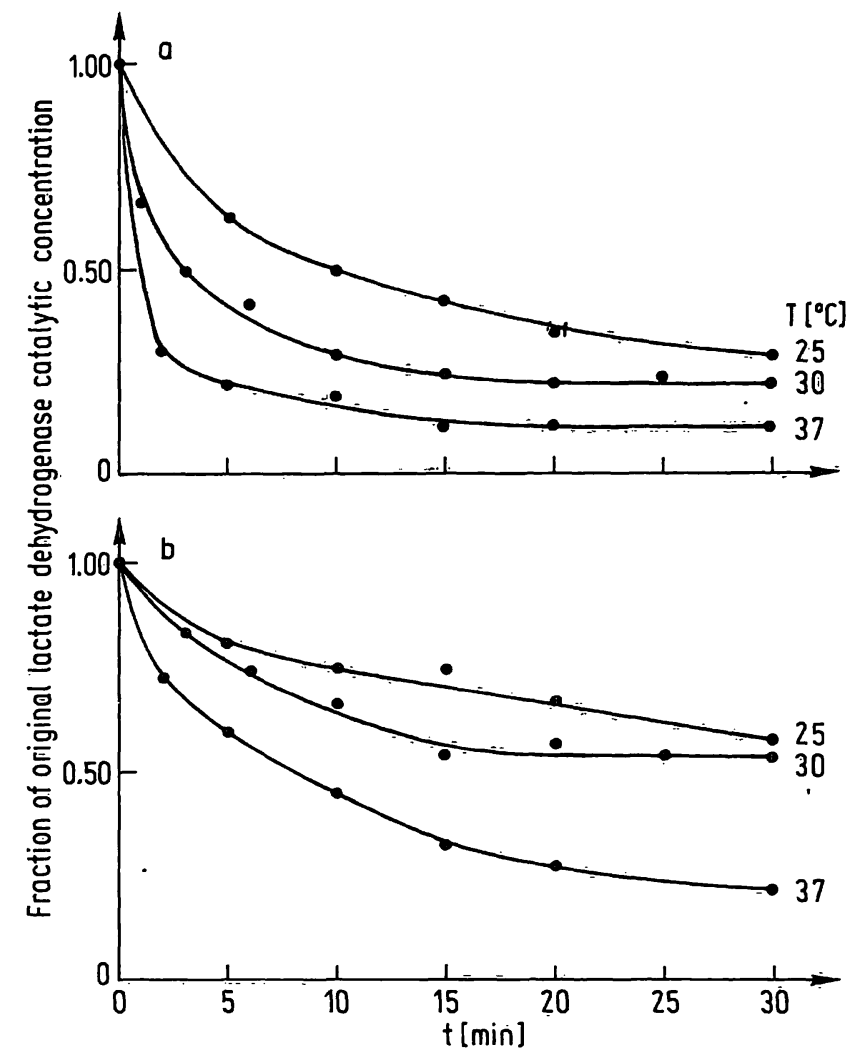

Fig. 1. Inhibition of lactate dehydrogenase activity by 1,6-hexanediol as a function of time and temperature. Lactate dehydrogenase activities in normal sera were measured manually after incubation with 1,6-hexanediol at

a) $700 \mathrm{mmol} / 1$

b) $500 \mathrm{mmol} / 1$

and at several time intervals.

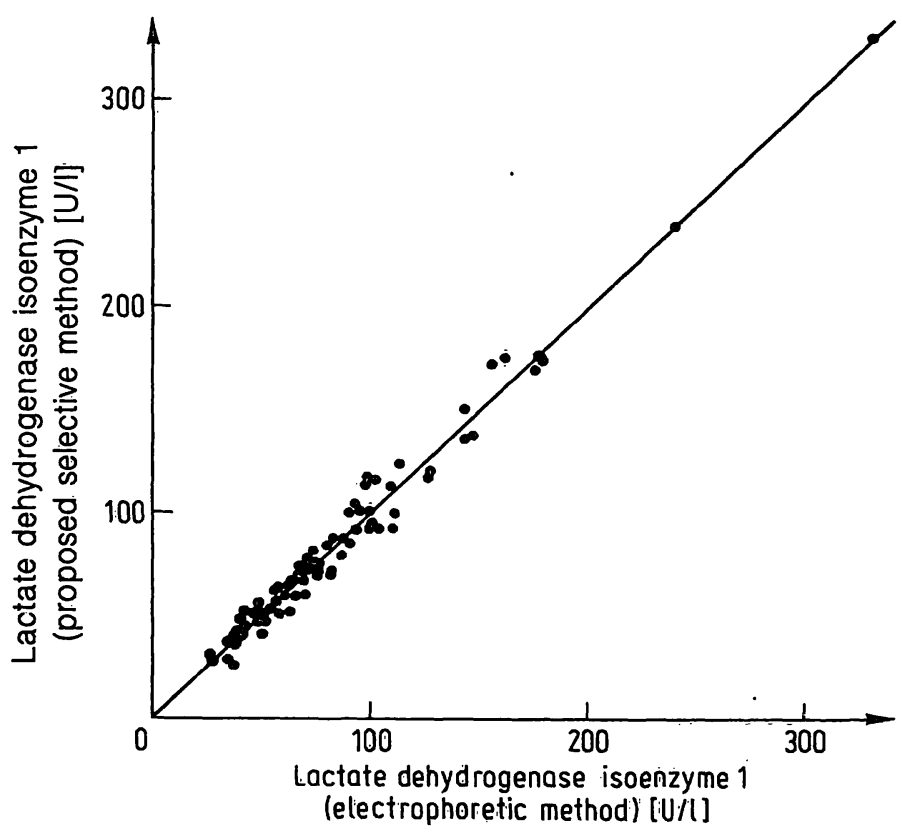

Fig. 2. Catalytic concentrations of lactate dehydrogenase isoenzyme LD-1 by the proposed selective method vs those measured by the electrophoretic method.

$y=1.019 x-1.54$

$\mathrm{r}=0.9958$

$\mathrm{n}=100$

$\overline{\mathrm{x}}=91.82$

$\dot{\bar{y}}=92.10$

$s_{\mathrm{yx}}=8.08$ 
Tab. 1. Effect of 1,6-hexanediol concentrations on the measurement of the activity of lactate dehydrogenase isoenzyme LD-1.

After inhibition by 1,6-hexanediol at a final concentration of After electro-

\begin{tabular}{llll}
\hline $650 \mathrm{mmol} / \mathrm{l}$ & $700 \mathrm{mmol} / \mathrm{l}$ & $750 \mathrm{mmol} / \mathrm{l}$ & $800 \mathrm{mmol} / \mathrm{l}$
\end{tabular}

\begin{tabular}{|c|c|c|c|c|c|}
\hline $\begin{array}{l}\text { Normal sera } \\
(n=7)\end{array}$ & $37.9 \pm 3.0$ & $26.7 \pm 2.5$ & $25.8 \pm 3.2$ & $24.9 \pm 3.3$ & $26.3 \pm 2.7$ \\
\hline $\begin{array}{l}\text { Patients' sera } \\
\text { (liver disease } n=7 \text { ) }\end{array}$ & & $15.9 \pm 6.4$ & & & $15.5 \pm 3.8$ \\
\hline $\begin{array}{l}\text { Patients' sera } \\
\text { (heart disease } n=7 \text { ) }\end{array}$ & & $32.7 \pm 10.6$ & & & $33.7 \pm 8.4$ \\
\hline
\end{tabular}

Numerals are lactate dehydrogenase $\%$ total serum activity (mean $\pm 2 \mathrm{SD}$, standard deviation). n: sample size

\section{Other enzyme activities in the presence of hexanediol}

We also measured activities of alkaline phosphatase, $\gamma$-glutamyltransferase, aspartate aminotransferase, alanine aminotransferase and creatine kinase after addition of hexanediol solution (final concentration of $700 \mathrm{mmol} / \mathrm{l})$. From the least-squares and Student's t-test parameters, essentially no differences between data of each enzyme activity measured before and after the addition of inhibitor were observed $(p<0.025, \mathrm{df}=74)$, but creatine kinase activities were about $10 \%$ inhibited by $700 \mathrm{mmol} / 1$ of hexanediol.

\section{Practice in acute myocardial infarction}

As we were able to obtain sera from patients with acute myocardial infarction, we measured their LD1 isoenzyme activities by the proposed selective method, by the electrophoretic and by the immunochemical, Roche Isomune method (tab. 2). Creatine kinase isoenzyme $\mathrm{MB}$ activity in each patient was $26.0 \%$ in case M.T. and $7.6 \%$ in case Y.K. at the onset. The results obtained by these three different methods during the first 3 days or 2 days were in close agreement.

\section{Discussion}

Measurement of the lactate dehydrogenase isoenzyme LD-1 level is required in the diagnosis of suspected myocardial infarction and in the use of thrombolytic therapy $(3,8)$, and in the diagnosis of renal disease, etc. $(9-11)$.

We previously described a manual inhibition method, using 1,6-hexanediol as an inhibitor of the M-subunit (7). In the present study we have developed a rapid method to replace the manual inhibition method.

In the manual method, we measured enzyme activities after incubation of serum with the inhibitor for 15 min at $30^{\circ} \mathrm{C}$ and immediately after dilution with the reaction medium. In the analysis by the Clynalyzer, it is difficult to ensure an incubation time of precisely 15 min before analysing each sample, but no changes of activities were observed after incubation for longer than $15 \mathrm{~min}$ as shown in the figure 1. Furthermore, when the samples are diluted in the reaction medium, the inhibition is completely abolished. However, it is desirable that the activities are measured automatically throughout the whole process under the same conditions as in the manual method. Another type of automated system, for example, the centrifugal

Tab. 2. Activity of serum lactate dehydrogenase isoenzyme LD-1 in acute myocardial infarction.

\begin{tabular}{|c|c|c|c|c|}
\hline Patients & & $\begin{array}{l}\text { Roche Isomune method } \\
\text { LD-1 isoenzyme }\end{array}$ & $\begin{array}{l}\text { Electrophoretic method } \\
\text { LD-1 isoenzyme }\end{array}$ & $\begin{array}{l}\text { Inhibition method } \\
\text { by } 1,6 \text {-hexanediol } \\
\text { LD-1 isoenzyme }\end{array}$ \\
\hline M.T. & $\begin{array}{l}\text { At the onset of chest pain } \\
2 \text { days after the onset } \\
4 \text { days after the onset }\end{array}$ & $\begin{array}{l}59.4 \% \\
56.8 \% \\
59.4 \%\end{array}$ & $\begin{array}{l}57.5 \% \\
53.9 \% \\
52.7 \%\end{array}$ & $\begin{array}{l}56.8 \% \\
53.2 \% \\
50.4 \%\end{array}$ \\
\hline Y.K. & $\begin{array}{l}\text { At the onset of chest pain } \\
\text { The } 2 \text { nd day after the onset }\end{array}$ & $\begin{array}{l}61.5 \% \\
48.7 \%\end{array}$ & $\begin{array}{l}51.9 \% \\
51.7 \%\end{array}$ & $\begin{array}{l}51.9 \% \\
50.8 \%\end{array}$ \\
\hline
\end{tabular}

Procedures for the Isomune, electrophoretic and inbibition methods are given in the text. 
system, in which the incubation period and temperature can be adjusted as necessary for the inhibition, might be more suitable.

The minimal concentration of 1,6-hexanediol necessary in the selective method for measurement of LD-1 isoenzyme was found to be $700 \mathrm{mmol} / \mathrm{l}$. An essentially acceptable inter-assay coefficient of variation was obtained in precision studies under these conditions. An excellent correlation was obtained between the selective method and the conventional electrophoretic method, when patients' sera with various levels of lactate dehydrogenase activities were used. We found this method was reliable for the rapid quantification of LD-1 isoenzyme activity in serum. However, it was difficult for us to distinguish a leukaemia case from liver disease or normal subjects, for example, the case with low LD-1 and high LD-3 isoenzyme activities

\section{References}

1. Seckinger, 'L. D., Vazquez, D. A., Rosenthal, P. K. \& Mendizabal, R. C. (1983) Amer. J. Clin. Pathol. 80, 164169.

2. Jablonsky, G., Leung, F. Y. \& Henderson, A. R. (1985) Clin. Chem. 31, 1621-1624.

3. Adan, J., Bernstein, L. H. \& Babb, J. (1986) Clin. Chem. $32,624-628$.

4. Henderson, A. R. (1983) in: Methods of Enzymatic Analysis (Bergmeyer, H. U., Bergmeyer, J. \& Grassl, M., eds.), Vol. III, Enzymes I, 3rd ed., pp. 138-155, Verlag Chemie, Weinheim.

5. Hunter, I., Attock, B. \& Palmer, T. (1983) Clin. Chim. Acta $135,72-82$. (isoenzymes \%: LD-1 12.7, LD-2 39.3, LD-3 34.8, LD-4 11.7, LD-5 1.5) from the case with low LD-1 and high LD-5 isoenzyme activities (LD-1 19.8, LD-2 22.3, LD-3 10.9, LD-4 3.9, LD-5 43.1). This proposed selective method seems to be suitable for the determination of the activity of lactate dehydrogenase isoenzyme LD-1 in the diagnosis of suspected myocardial infarction.

The addition of 1,6-hexanediol as an inhibitor did not interfere with the measurement of other enzyme activities, but we must report a slight decrease of creatine kinase activities caused by hexanediol.

\section{Acknowledgement}

We thank Mr. Shoichi Sasajima MT of Central Clinical Laboratory of Kanazawa University Hospital for providing, blood serum specimens and help on analyses by automatic analyser.

6. Eckfeldt, J. H., Kershawi, M. J. \& Lewis, L. A. (1984) Clin. Chem. 30, $1821-1824$.

7. Tanishima, K., Hayashi, T., Matsushima, M. \& Mochikawa, Y. (1985) Clin. Chem. 31, 1175-1177.

8. Kiwong, T. C., Fitzpatrick, P. G. \& Rothbard, R. L. (1984) Clin. Chem. 30, $731-734$.

9. Ringoir, S. \& Wieme, R. J. (1972) Clin. Chim. Acta 42, $315-320$.

10. Ringoir, S. \& Plum, J. (1975) Clin. Chim. Acta 60, 379383.

11. Foo, A. Y., Nemesanzky, E. \& Rosalki, S. B. (1981) Ann. Clin. Biochem. 18, 232-235.

Kiyoh Tanishima, Ph. D.

Division of Clinical Laboratory Sciences

School of Allied Medical Professions

Kanazawa University

11-80, Kodatsuno 5-chome, Kanazawa

Japan 920 